\title{
Amorphous Cobalt Vanadium Oxide as a Highly Active Electrocatalyst for Oxygen Evolution
}

\author{
Laurent Liardet and Xile $\mathrm{Hu}^{*}$ (1)
}

Laboratory of Inorganic Synthesis and Catalysis, Institute of Chemical Sciences and Engineering, Ecole Polytechnique Fédérale de Lausanne (EPFL), 1015 Lausanne, Switzerland

\section{Supporting Information}

ABSTRACT: The water-splitting reaction provides a promising mechanism to store renewable energies in the form of hydrogen fuel. The oxidation half-reaction, the oxygen evolution reaction (OER), is a complex four-electron process that constitutes an efficiency bottleneck in water splitting. Here we report a highly active OER catalyst, cobalt vanadium oxide. The catalyst is designed on the basis of a volcano plot of metal-OH bond strength and activity. The catalyst can be synthesized by a facile hydrothermal route. The most active pure-phase material $\left(a-\mathrm{CoVO}_{x}\right)$ is X-ray amorphous and provides a $10 \mathrm{~mA} \mathrm{~cm} \mathrm{c}^{-2}$ current density at an overpotential of $347 \mathrm{mV}$ in $1 \mathrm{M} \mathrm{KOH}$ electrolyte when immobilized on a flat substrate. The synthetic method can also be applied to coat a high-surface-area substrate such as nickel foam. On this three-dimensional substrate, the $a-\mathrm{CoVO}_{x}$ catalyst is highly active, reaching $10 \mathrm{~mA} \mathrm{~cm}{ }^{-2}$ at $254 \mathrm{mV}$ overpotential, with a Tafel slope of only 35 $\mathrm{mV} \mathrm{dec}^{-1}$. This work demonstrates $a-\mathrm{CoVO}_{x}$ as a promising electrocatalyst for oxygen evolution and validates $\mathrm{M}-\mathrm{OH}$ bond strength as a practical descriptor in OER catalysis.

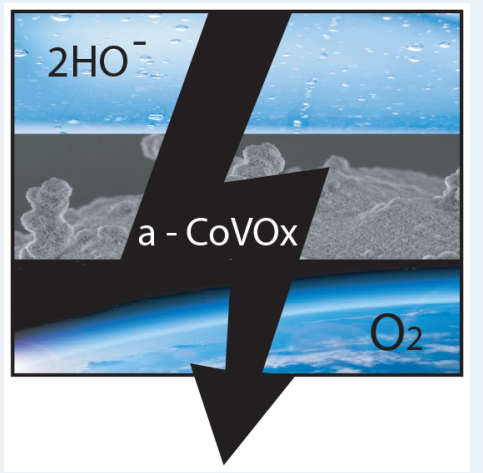

KEYWORDS: oxygen evolution reaction, cobalt vanadium oxide, electrocatalyst, volcano plot, amorphous materials

\section{INTRODUCTION}

Water splitting $\left(2 \mathrm{H}_{2} \mathrm{O} \rightarrow 2 \mathrm{H}_{2}+\mathrm{O}_{2}\right)$ is an attractive reaction to enable the storage of intermittent renewable energies such as sunlight and wind, in the form of a chemical fuel, namely, hydrogen. ${ }^{1}$ Water splitting has a bottleneck that arises from its four-electron oxidative half-reaction, the oxygen evolution reaction (OER), $2 \mathrm{H}_{2} \mathrm{O} \rightarrow 4 \mathrm{H}^{+}+\mathrm{O}_{2}+4 \mathrm{e}^{-}$. In order to accelerate its sluggish kinetics and to achieve the production of hydrogen fuel at a practicable rate, catalysts are necessary. Stateof-the-art OER catalysts, based on precious metals such as $\mathrm{IrO}_{2}$ and $\mathrm{RuO}_{2}$, can perform the OER in acidic solutions with an overpotential close to $200 \mathrm{mV}$. $^{2}$ However, the scarcity and cost of those metals limit their potential for large-scale applications. Developing earth-abundant OER catalysts is therefore crucial. A growing number of catalysts based on earth-abundant transition-metal oxides have been studied for OER in alkaline conditions, some of which are reported to surpass $\mathrm{IrO}_{2}$ and $\mathrm{RuO}_{2}$ in activity. ${ }^{3-5}$

While the development of OER catalysts remains mostly empirical, significant work has been done to search for theoretical guidelines for catalyst discovery. The "descriptor" approach is appealing because it allows systematic tuning of catalysts using a single measurable or calculable parameter. Some of the most successful descriptors for OER include the $\mathrm{M}-\mathrm{OH}$ bond strength, the $\mathrm{e}_{\mathrm{g}}$ occupancy and $\left(\Delta G \mathrm{O}^{*}-\right.$ $\left.\Delta G H O^{*}\right){ }^{6-8}$ Application of these descriptors in experimental work, however, is limited. ${ }^{7,9}$

We recently measured the intrinsic activity of a range of transition-metal oxide thin film catalysts and found the activity correlated with the $\mathrm{M}-\mathrm{OH}$ bond strength proposed by Bockris and Otagawa in a volcano-type plot (Figure 1). ${ }^{6,10}$ Typically, with the descriptor approach, the correlation reveals neither the nature of the active species nor the physical origins of the activity of mixed oxide catalysts such as $\mathrm{NiFeO}_{x}$ and $\mathrm{CoFeO}_{x}$,

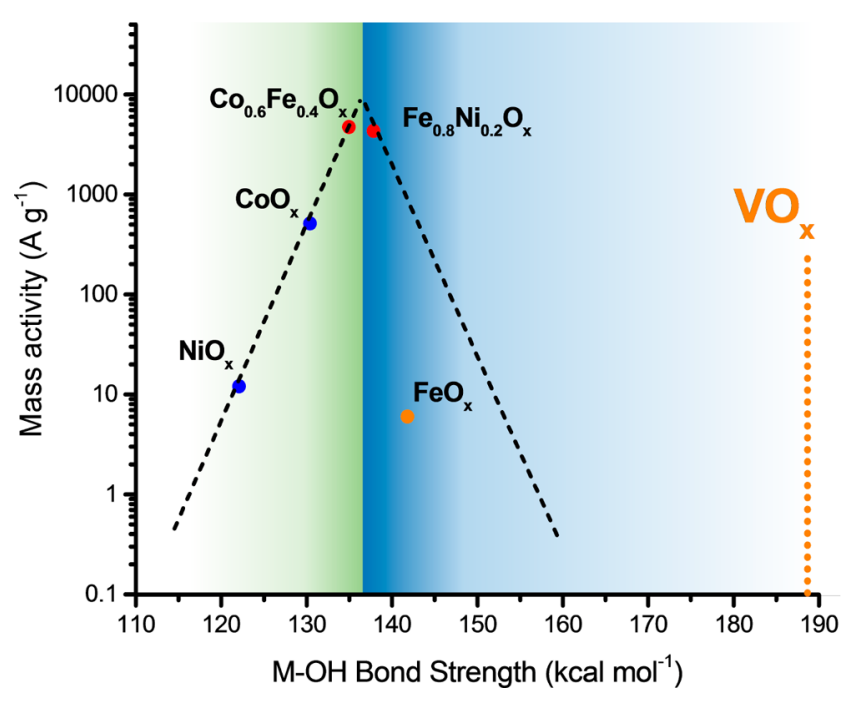

Figure 1. Volcano plot of OER activity versus $\mathrm{M}-\mathrm{OH}$ bond strength, modified from ref 10 with addition of theoretical $\mathrm{M}-\mathrm{OH}$ bond strength of vanadium oxide $\left(\mathrm{VO}_{x}\right)$ from ref 6 .

Received: September 19, 2017

Revised: November 29, 2017

Published: December 6, 2017 
which is still under investigation and actively debated. ${ }^{11,12}$ However, it explains the superior activity of $\mathrm{NiFeO}_{x}$ and $\mathrm{CoFeO}_{x}$ in an approximate, yet much simpler way, in that $\mathrm{NiO}_{x}$ and $\mathrm{CoO}_{x}$ are on a different branch of the volcano plot from $\mathrm{FeO}_{x}$, such that their mixtures may benefit from a balance of $\mathrm{M}-\mathrm{OH}$ bond strengths to reach optimal activity. Given that the presence of iron is essential in most highly active mixed metal oxide catalysts, we became interested in developing iron-free catalysts to enrich the repertoire of OER catalysts. Since $\mathrm{VO}_{x}$ sits in the same branch as $\mathrm{FeO}_{x}$ in the volcano plot, we turned our attention of $\mathrm{V}$-containing mixed oxides. As an early transition metal, $\mathrm{V}$ is rarely explored for OER with the exception of some recent studies. ${ }^{13-15}$ For example, Sun et al. described the promising OER activity of a NiV layered double hydroxide $(\mathrm{LDH}),{ }^{14}$ and Wang and co-workers showed lepidocrocite $\mathrm{VOOH}$ as a competent OER catalyst. ${ }^{15}$ According to the volcano plot, we predicted that $\mathrm{CoVO}_{x}$ might exhibit high OER activity since $\mathrm{CoO}_{x}$ and $\mathrm{VO}_{x}$ sit at the two opposite branches. We thus prepared amorphous $\mathrm{CoVO}_{x}$ catalysts via a simple hydrothermal method, and they indeed exhibit excellent OER activity.

\section{RESULTS AND DISCUSSION}

In order to produce a binary metal oxide made of cobalt and vanadium, a hydrothermal synthesis was performed in a Teflon lined stainless steel autoclave (see Experimental Section for details). Control samples were also prepared by using the same hydrothermal method with individual metal salts in order to obtain cobalt oxide and vanadium oxide $\left(\mathrm{CoO}_{x}\right.$ and $\left.\mathrm{VO}_{x}\right)$. The powdered catalysts were immobilized on a glassy carbon electrode, and cyclic voltammetry was performed in a $1 \mathrm{M}$ $\mathrm{KOH}$ electrolyte ( $\mathrm{pH}$ 13.6). The OER activity is presented in Figure 2. Each oxide was tested in normal $\mathrm{KOH}$ electrolyte, as well as in purified $\mathrm{Fe}$-free $\mathrm{KOH}$, where trace iron was removed according to a procedure reported by Trotochaud et al. ${ }^{12}$ The binary cobalt vanadium oxide (named $m-\mathrm{CoVO}_{x}$ in this work due to its mixed-phase composition, vide infra) exhibits high activity for water oxidation, reaching $10 \mathrm{~mA} \mathrm{~cm}^{-2}$ at an overpotential of 366 and $358 \mathrm{mV}$ in normal and $\mathrm{Fe}$-free $\mathrm{KOH}$, respectively. This current density is taken as a reference as it is the one expected at the anode in a $12.3 \%$ efficient solar watersplitting device under 1-sun illumination. ${ }^{4}$ The control samples made with the unary metal oxide constituents of this catalyst $\left(\mathrm{CoO}_{x}\right.$ and $\left.\mathrm{VO}_{x}\right)$ required higher overpotentials for the same current densities. It was found that the overpotentials for $m$ $\mathrm{CoVO}_{x}$ do not differ noticeably whether a trace amount of iron is present or not in the electrolyte. Thus, iron incorporation seemed not to play an essential role in the OER activity of this material, in contrast to $\mathrm{NiO}_{x}{ }^{5,12,16}$ The Tafel slopes are 65 (63) $\mathrm{mV} \mathrm{dec}{ }^{-1}$ for $m-\mathrm{CoVO}_{x}, 57$ (59) $\mathrm{mV} \mathrm{dec}^{-1}$ for $\mathrm{CoO}_{x}$, and 97 (142) $\mathrm{mV} \mathrm{dec}^{-1}$ for $\mathrm{VO}_{x}$ in normal $1 \mathrm{M} \mathrm{KOH}$ (with Fe-free $\mathrm{KOH}$ values in parentheses) (Figure $\mathrm{S} 1$ ).

The composition and crystallinity of both control samples $\left(\mathrm{CoO}_{x}\right.$ and $\left.\mathrm{VO}_{x}\right)$ and $m-\mathrm{CoVO}_{x}$ were analyzed by XRD (Figure $3 a)$. All three samples show evidence of crystallinity. The $m$ $\mathrm{CoVO}_{x}$ sample exhibits diffraction peaks similar to those of the control $\mathrm{CoO}_{x}$ sample (Figure S2a), and no crystalline cobalt vanadium oxide phase could be identified in the XRD pattern of $m-\mathrm{CoVO}_{x}$. The diffraction peaks of the $\mathrm{CoO}_{x}$ control sample correspond to a cobalt chloride carbonate hydroxide hydrate phase $\left(\mathrm{Co}\left(\mathrm{CO}_{3}\right)_{0.35} \mathrm{Cl}_{0.2}(\mathrm{OH})_{1.10} \cdot 1.74 \mathrm{H}_{2} \mathrm{O}\right.$, JSPDS 00-0380547) (Figure S2b,c). Therefore, the crystallinity of the $m$ $\mathrm{CoVO}_{x}$ sample is presumed to come from this cobalt chloride
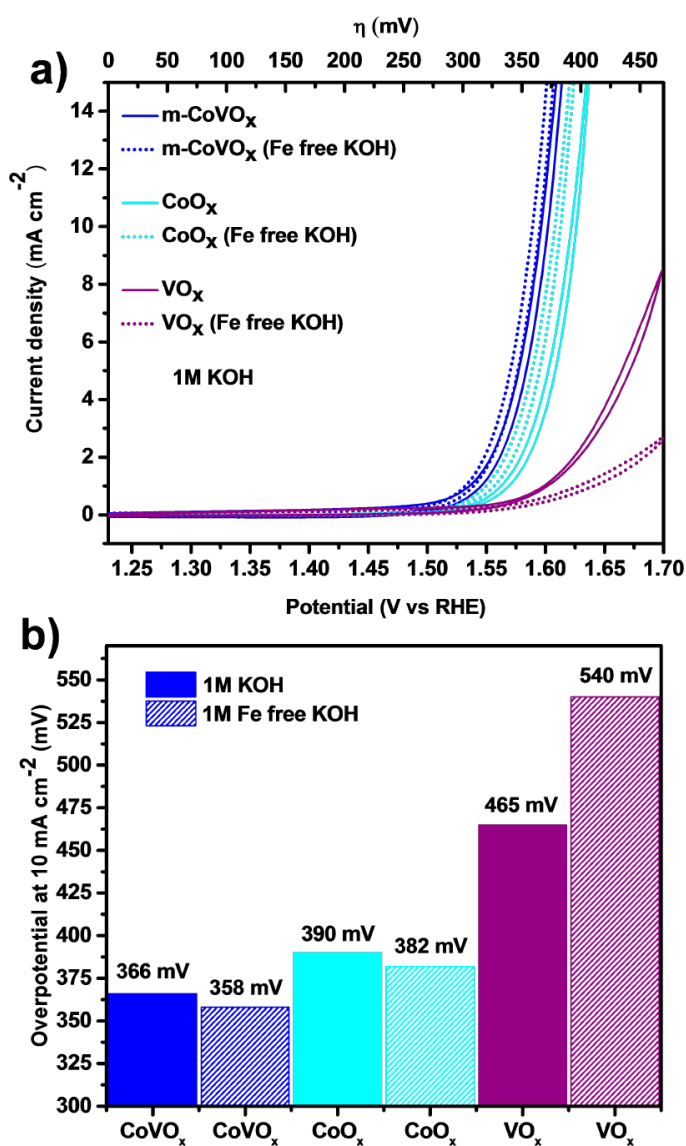

Figure 2. (a) Polarization curves for $m-\mathrm{CoVO}_{x}, \mathrm{CoO}_{x}$ and $\mathrm{VO}_{x}$ (loadings $140 \mu \mathrm{g} \mathrm{cm}^{-2}$ ) in $1 \mathrm{M} \mathrm{KOH}$ and $1 \mathrm{M} \mathrm{Fe-free} \mathrm{KOH}$. Scan rate: $10 \mathrm{mV} \mathrm{s}^{-1}$; $i R$ drop corrected. (b) Extracted overpotentials at 10 $\mathrm{mA} \mathrm{cm}{ }^{-2}$.

carbonate hydroxide hydrate phase, but not from crystalline cobalt vanadium oxide. The vanadium oxide $\left(\mathrm{VO}_{x}\right)$ control sample was identified as the haggite phase $\left(\mathrm{V}_{2} \mathrm{O}_{2}(\mathrm{OH})_{3}\right.$, JSPDS 01-072-1228) (Figure S2d).

The morphology of the different metal oxides was analyzed by SEM. Two types of structures were observed in the $m$ $\mathrm{CoVO}_{x}$ sample: the first is composed of nanoneedles, while the second is a more disorganized phase (Figure 3b). The nanoneedles can be attributed to the cobalt chloride carbonate hydroxide hydrate phase by comparison to the SEM image of $\mathrm{CoO}_{x}$ control sample (Figure S3). TEM of the disorganized phase reveals its polycrystalline nature and lattice fringes can be observed on the HR-TEM image (Figure S4a). In the STEMEDX mapping, cobalt and vanadium are continuously observed as a mixture, and the cobalt chloride carbonate hydroxide hydrate phase could be identified as red particles on the $\mathrm{Co}-\mathrm{V}$ map (Figure S4b). Thus, the $m-\mathrm{CoVO}_{x}$ sample here is composed of a heterogeneous mixture with a crystalline cobalt chloride carbonate hydroxide hydrate phase and an X-ray amorphous phase containing cobalt and vanadium.

The hydrothermal method was further applied to grow the $m-\mathrm{CoVO}_{x}$ sample directly on nickel foam (NF). The deposited catalyst is also composed of a heterogeneous mixed phase. Intricate nanoleaves and microscopic square crystals can be observed by SEM (Figure S5). The catalyst on nickel foam reached $10 \mathrm{~mA} \mathrm{~cm}^{-2}$ at overpotentials of 293 and $298 \mathrm{mV}$ in 1 $\mathrm{M} \mathrm{KOH}$ and $1 \mathrm{M}$ Fe-free $\mathrm{KOH}$, respectively (Figure S6a). The stability of this catalyst was evaluated by monitoring the 
a)

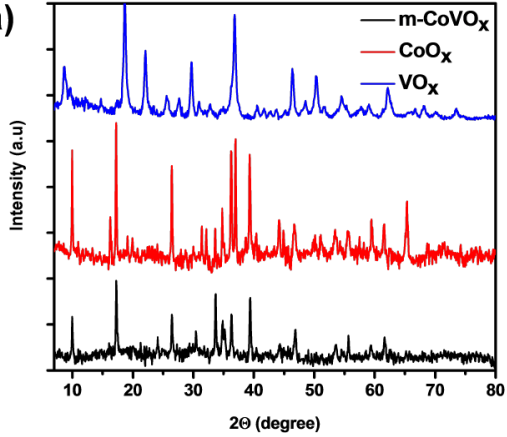

b)

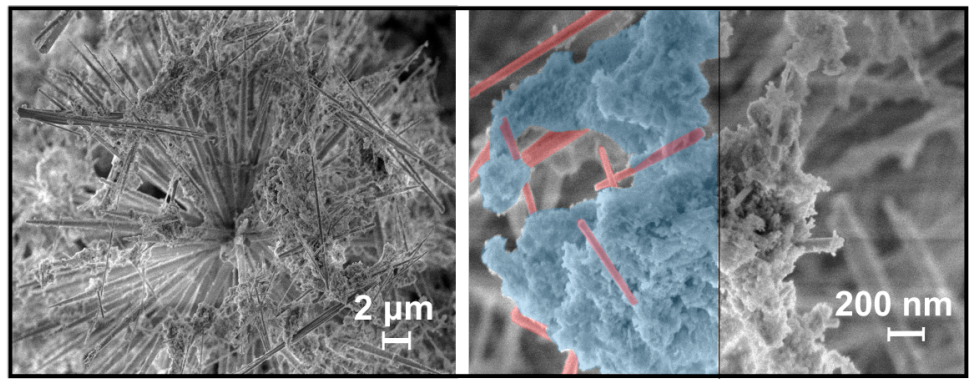

Figure 3. (a) XRD patterns of $m-\mathrm{CoVO}_{x}, \mathrm{CoO}_{x}$ and $\mathrm{VO}_{x}$ samples. (b) SEM images of $m$-CoVO . The disorganized phase is highlighted in blue and the nanoneedles in red.

a)
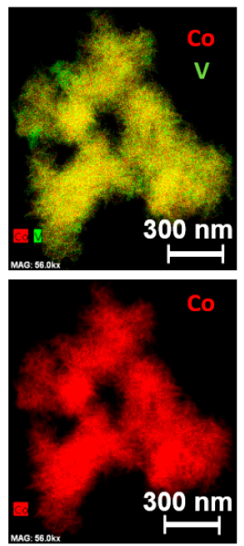

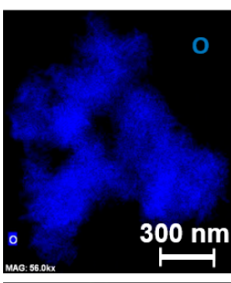

b)

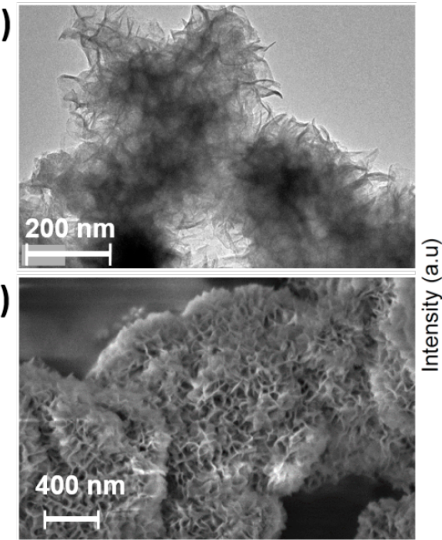

d)

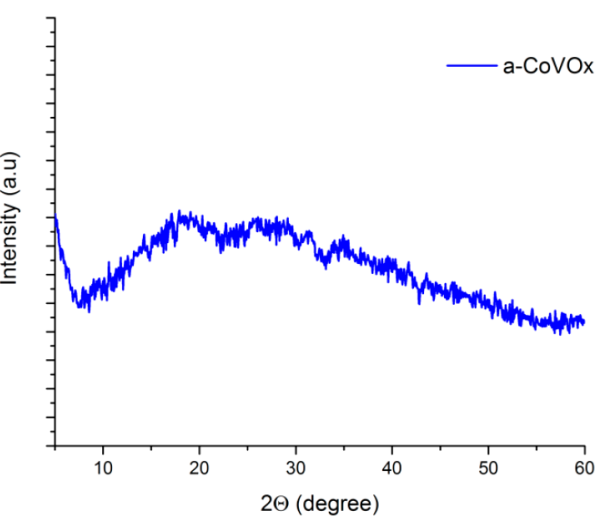

Figure 4. (a) STEM-EDX map of $a$-CoVO $x^{*}$ (b) TEM image of $a$-CoVO $x^{*}$ (c) SEM image of $a$-CoVO $x^{\text {. }}$ (d) XRD pattern of $a$-CoVO $x^{\text {. }}$.

potential at $10 \mathrm{~mA} \mathrm{~cm}{ }^{-2}$. No significant changes were observed during $15 \mathrm{~h}$ of electrolysis (Figure S6b), indicating good stability.

Because the $m-\mathrm{CoVO}_{x}$ sample contains a crystalline Co oxide that was less active toward OER (vide supra), we considered this Co phase as an impurity and concentrated our efforts in synthesizing a pure single-phase cobalt vanadium oxide catalyst in order to yield higher activity. This was successful using the same hydrothermal method but with the addition of trisodium citrate as an additive. Different ratios of cobalt and vanadium salts were used in order to tune the composition of the oxide and optimize the catalytic activity. Five different $\mathrm{Co}: \mathrm{V}$ ratios were tried (Co:V mole ratios in the hydrothermal solution: $5: 1$, $3: 1,1: 1,1: 3$ and 1:5), and the obtained materials were evaluated for OER on a glassy carbon electrode. All catalysts were scanned by cyclic voltammetry in $1 \mathrm{M} \mathrm{KOH}$ and $1 \mathrm{M} \mathrm{Fe}-$ free $\mathrm{KOH}$, although the presence of trace iron in the $\mathrm{KOH}$ did not affect OER activity (Figure S7a). The Co:V ratio yielding the highest activity was 3:1 (Figure S7b).

The STEM images and EDX mapping of the cobalt vanadium oxide with a $3: 1 \mathrm{Co:V}$ ratio (Figure $4 \mathrm{a}$ ) confirmed the formation of cobalt vanadium oxide phase. Both Co and $\mathrm{V}$ are homogeneously dispersed throughout the sample, and neither $\mathrm{CoO}_{x}$ nor $\mathrm{VO}_{x}$ particles were observed. The sample has a nanosheet-like morphology (Figure 4b,c), and the absence of diffraction peaks in its XRD pattern suggests it is X-ray amorphous and that no crystalline $\mathrm{CoO}_{x}$ or $\mathrm{VO}_{x}$ impurities are present. This confirms the formation of a pure-phase cobalt vanadium oxide (Figure $4 \mathrm{~d}$ ), which is labeled as $a-\mathrm{CoVO}_{x}$.
When deposited on nickel foam, the $a-\mathrm{CoVO}_{x}$ has a similar morphology and homogeneously coats the three-dimensional substrate (Figure S8).

The $a-\mathrm{CoVO}_{x}$ catalyst was further characterized by X-ray photoelectron spectroscopy (XPS) (Figure 5). The binding energy (BE) of the Co $2 \mathrm{p}_{3 / 2}$ signal is $781.1 \mathrm{eV}$. Moreover, outer-shell excitation satellite peaks are visible at lower $\mathrm{BE}$, indicating high-spin $\mathrm{Co}^{2+} .{ }^{17}$ Vanadium is incorporated into the catalyst in the +4 oxidation state, as suggested by the $\mathrm{V} 2 \mathrm{p}_{3 / 2}$ peak at a $\mathrm{BE}$ of $516.5 \mathrm{eV}{ }^{18}$ The signal at $288.3 \mathrm{eV}$ in the $\mathrm{C} 1 \mathrm{~s}$ region is representative of carbon atoms in a carbonate group. The signal at a $\mathrm{BE}$ of 531.5 and $530.0 \mathrm{eV}$, in the $\mathrm{O} 1 \mathrm{~s}$ region, is representative of oxygen atoms in $\mathrm{OH}^{-}$groups and $\mathrm{O}^{2-}$ in transition-metal (oxy)hydroxides, respectively. The signal at $\mathrm{BE}$ $=532.3 \mathrm{eV}$, characteristic of oxygen atoms in a carbonate group, further suggests the presence of this group in the material. ${ }^{19}$ The atomic ratio of cobalt to vanadium $(\mathrm{Co}: \mathrm{V})$ determined by XPS is approximately $75 \% / 25 \%(3: 1)$ and is consistent with the ratio of the two metal salts in the precursor solution for the hydrothermal synthesis. However, this agreement was somewhat fortuitous as there was otherwise a modest discrepancy between the ratios of the metal salts used in the precursor solutions and those of final catalysts for the other ratios used (Table S1).

As we used a sodium salt (trisodium citrate) as an additive to synthesize the pure phase $a-\mathrm{CoVO}_{x}$, we investigated if sodium incorporation could influence the OER activity of this material. We found that $a-\mathrm{CoVO}_{x}$ does not contain sodium in its structure after the hydrothermal synthesis (Figure S9a). We 

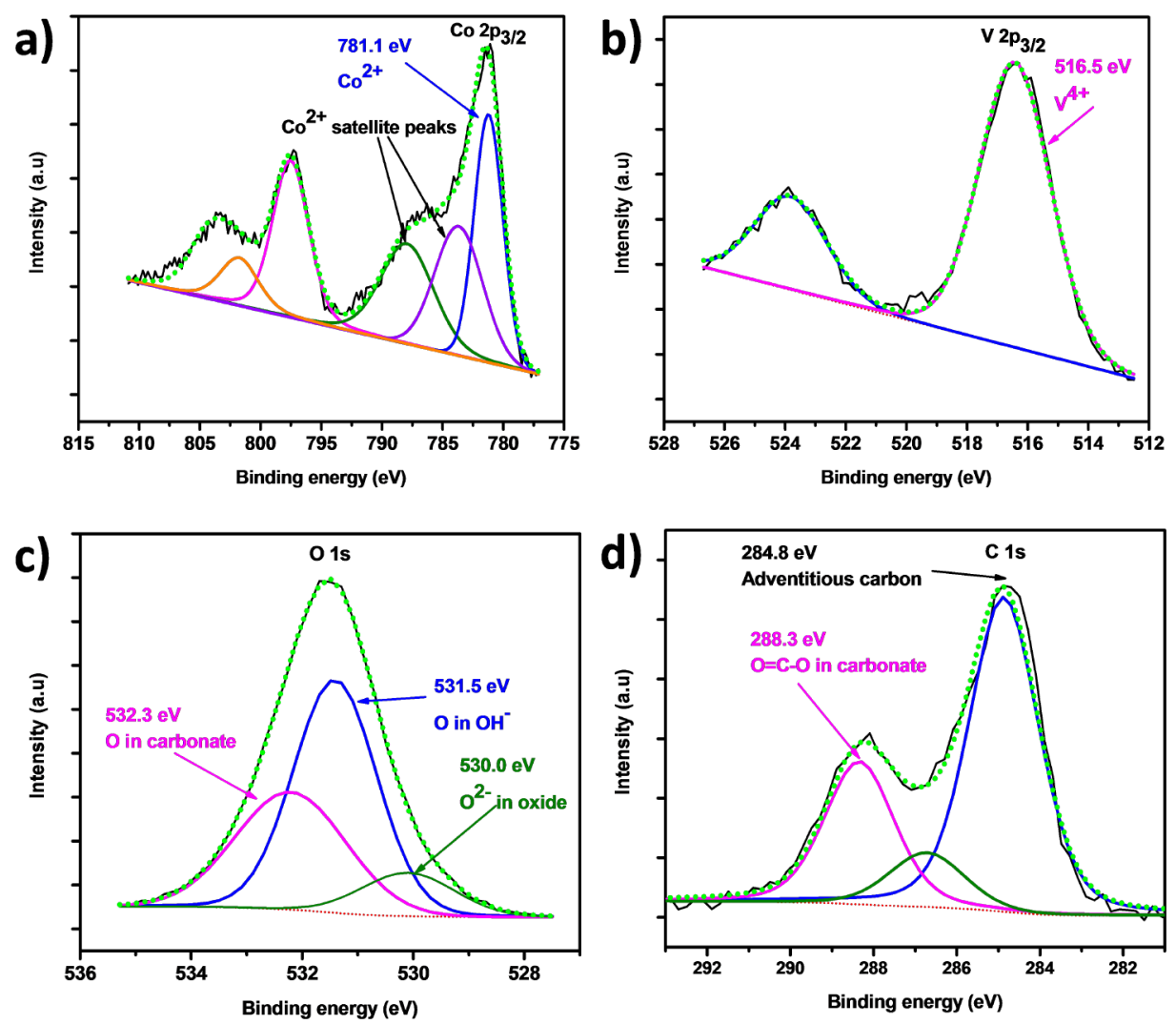

Figure 5. XPS spectra of $a-\mathrm{CoVO}_{x}$ with high resolution spectra of (a) Co $2 \mathrm{p}_{3 / 2}$ region, (b) $\mathrm{V} 2 \mathrm{p}_{3 / 2}$ region, (c) O 1 s region, and (d) C 1s region.

performed cyclic voltammetry in Fe-free $\mathrm{NaOH}$ in order to incorporate sodium, and we determined that the OER activity of $a-\mathrm{CoVO}_{x}$ did not increase in this electrolyte compared to $\mathrm{Fe}-$ free $\mathrm{KOH}$ (Figure S9b).

The catalytic activity of $a-\mathrm{CoVO}_{x}$ was measured on glassy carbon and nickel foam (Figure 6a,b). In the first case the $a$ $\mathrm{CoVO}_{x}$ reached $10 \mathrm{~mA} \mathrm{~cm}{ }^{-2}$ at an overpotential of 347 and $351 \mathrm{mV}$ in $1 \mathrm{M} \mathrm{KOH}$ and $1 \mathrm{M} \mathrm{Fe}$-free $\mathrm{KOH}$ electrolytes, with Tafel slopes of 51 and $49 \mathrm{mV} \mathrm{dec}^{-1}$, respectively. When deposited on nickel foam the catalysts delivered the same current density at an overpotential of 254 and $262 \mathrm{mV}$ in standard and iron-free $1 \mathrm{M} \mathrm{KOH}$, with Tafel slopes of 35 and $34 \mathrm{mV} \mathrm{dec}{ }^{-1}$, respectively. The overpotential for $a-\mathrm{CoVO}_{x}$ compares well with other cobalt vanadium oxide catalysts, such as $\mathrm{Co}_{2} \mathrm{~V}_{2} \mathrm{O}_{7}(340 \mathrm{mV}){ }^{20}{ }^{20} \mathrm{Co}_{3} \mathrm{~V}_{2} \mathrm{O}_{8}(359 \mathrm{mV}),{ }^{21}$ and $\mathrm{Co}_{3} \mathrm{~V}_{2} \mathrm{O}_{8}$ nanoroses $(391 \mathrm{mV}) .{ }^{22}$ Additionally, $a-\mathrm{CoVO}_{x}$ is highly competitive with other cobalt-containing catalysts on nickel foam (NF), such as $\mathrm{Co}_{3} \mathrm{O}_{4} / \mathrm{NF}(497 \mathrm{mV}){ }^{23} \mathrm{NiCo} \mathrm{LDH} / \mathrm{NF}$ $(420 \mathrm{mV}),{ }^{24} \mathrm{NiCo} \mathrm{DH} / \mathrm{N}$-graphene $/ \mathrm{NF}(350 \mathrm{mV}),{ }^{25} \mathrm{CoP} / \mathrm{NF}$ $(290 \mathrm{mV}),{ }^{26} \mathrm{CoFeO}_{x} / \mathrm{NF}$ and $\mathrm{NiCoFeO}_{x} / \mathrm{NF}(260$ and 240 $\mathrm{mV}) \cdot{ }^{10}$ In addition, the $a-\mathrm{CoVO}_{x}$ immobilized on NF exhibited considerable catalytic durability and stability, with only a moderate increase of $30 \mathrm{mV}$ in overpotential after $15 \mathrm{~h}$ of constant anodic polarization at $10 \mathrm{~mA} \mathrm{~cm}{ }^{-2}$ (Figure 6c). After the long-term stabilily test, the morphology and elemental composition of $a-\mathrm{CoVO}_{x}$ were investigated by SEM and STEM-EDX. Structural degradation can be observed but the $a$ $\mathrm{CoVO}_{x}$ catalyst retains its nanosheet-like morphology (Figure $\mathrm{S} 10 \mathrm{a}, \mathrm{b}, \mathrm{c})$. The EDX mapping indicates that $\mathrm{Co}$ and $\mathrm{V}$ are still homogeneously dispersed inside the material (Figure S10d), and no inclusion of nickel could be observed during the $15 \mathrm{~h}$ electrolysis (Figure S10e) Furthermore, the faradaic efficiency for OER was measured to be close to $100 \%$ (Figure S11).

Our group recently reported a volcano plot that compared the mass activity trends of different electrodeposited transitionmetal (oxy)hydroxides based on their respective $\mathrm{M}-\mathrm{OH}$ bond strength. ${ }^{10}$ Even though the $\mathrm{M}-\mathrm{OH}$ bond strength is not a definitive descriptor of OER activity, Bockris and Otagawa proposed that this parameter should allow the extraction of activity trends for metal oxides. ${ }^{6,27}$ The bond strength $\mathrm{D}(\mathrm{M}-$ $\mathrm{OH})$ was defined as the sum of the heterolytic $\mathrm{D}_{\text {ion }}(\mathrm{M}-\mathrm{OH})$ and homolytic $\mathrm{D}_{\text {cov }}(\mathrm{M}-\mathrm{OH})$ bond dissociation of a metal hydroxide in the $\mathrm{M}^{\mathrm{III}}(\mathrm{OH})_{3}$ form. For the determination of $\mathrm{D}(\mathrm{M}-\mathrm{OH})$ in our $a-\mathrm{CoVO}_{x}$, we simply treated them as a physical binary mixture and used a linear combination of the bond strengths of the respective unary metal hydroxides (Table S2). By taking into consideration the mass activity of $a-\mathrm{CoVO}_{x}$ with different $\mathrm{Co:V}$ atomic ratios (Figure S12, Table S3), we could correlate it with their respective $\mathrm{M}-\mathrm{OH}$ bond strength and a volcano-shaped plot was obtained (Figure 7). The agreement between the theoretical lines and the experimental data is surprisingly good given the simplifications made in the construction of this plot. The optimal catalyst found experimentally, $a-\mathrm{Co}_{0.75} \mathrm{~V}_{0.25} \mathrm{O}_{x}$, sits close to the top of the volcano.

\section{CONCLUSIONS}

On the basis of the volcano plot of OER activity versus $\mathrm{M}-\mathrm{OH}$ bond strength, cobalt vanadium oxide was predicted to be a highly active OER catalyst. A simple hydrothermal route was thus developed to prepare the targeted compound. A purephase, amorphous cobaltvanadium oxide $\left(a-\mathrm{CoVO}_{x}\right)$ was obtained and characterized by XRD, XPS, SEM, and STEM- 

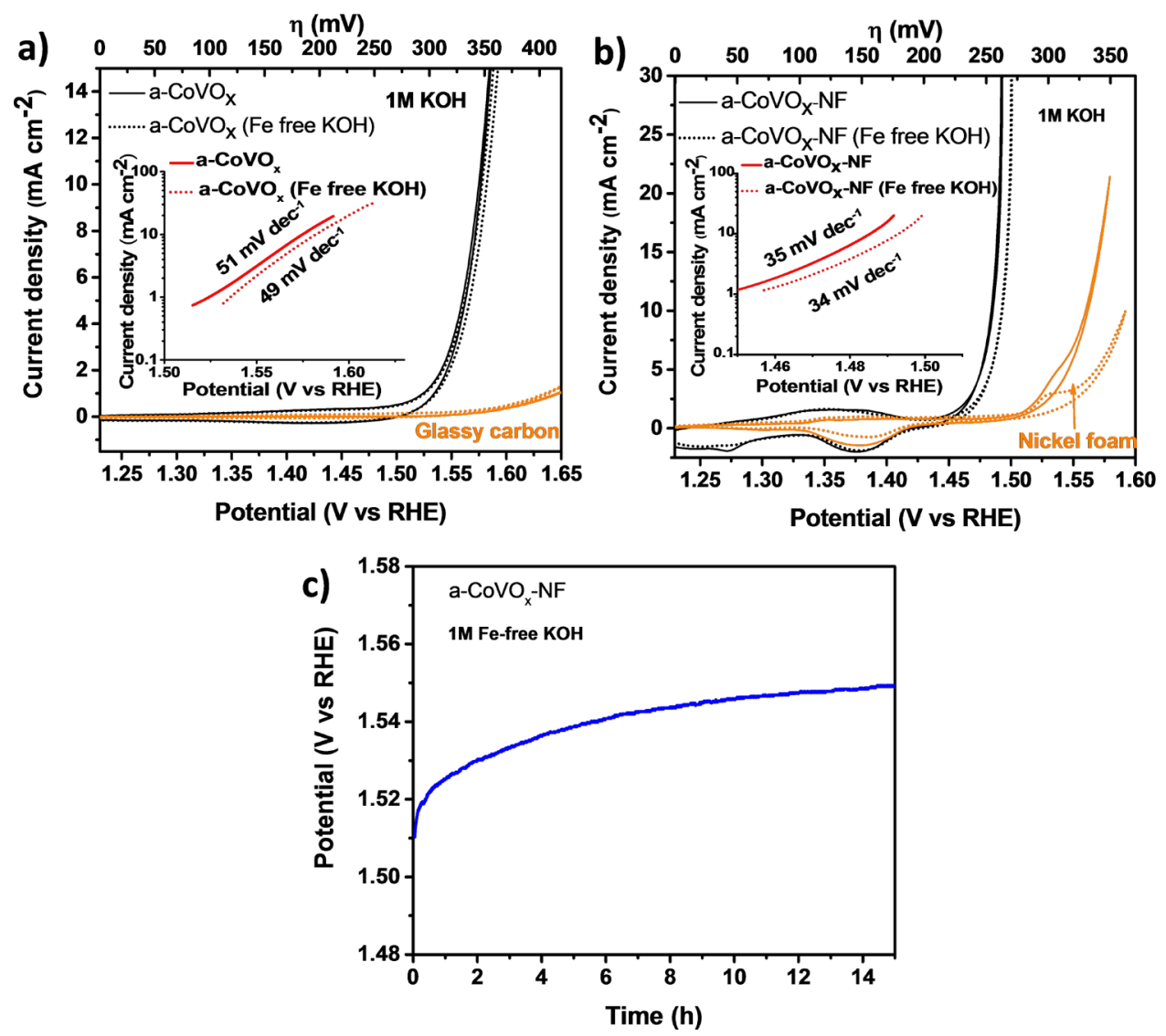

Figure 6. (a) Polarization curves for $a-\mathrm{CoVO}_{x}$ on glassy carbon (loading $140 \mu \mathrm{g} \mathrm{cm}^{-2}$ ) in $1 \mathrm{M} \mathrm{KOH}$ and $1 \mathrm{M} \mathrm{Fe}-$ free $\mathrm{KOH}$. Scan rate: $10 \mathrm{mV} \mathrm{s}{ }^{-1}$; $i R$ drop corrected. (b) Polarization curves for $a$-CoVO $x$ on nickel foam in $1 \mathrm{M} \mathrm{KOH}$ and $1 \mathrm{M}$ Fe-free KOH. Scan rate: $1 \mathrm{mV} \mathrm{s}^{-1}$; $i R$ drop corrected. (c) Stability of the applied potential of $a-\mathrm{CoVO}_{x}$ on nickel foam at $10 \mathrm{~mA} \mathrm{~cm}$.



Figure 7. Volcano plot of the mass activity vs $\mathrm{M}-\mathrm{OH}$ bond strength of various $a-\mathrm{Co}_{y} \mathrm{~V}_{1-y} \mathrm{O}_{x}$ and control cobalt and vanadium oxides samples.

EDX. This $a-\mathrm{CoVO}_{x}$ catalyst showed high catalytic activity for oxygen evolution. On a flat glassy carbon electrode, the catalyst reached $10 \mathrm{~mA} \mathrm{~cm}{ }^{-2}$ at an overpotential of $347 \mathrm{mV}$ in $1 \mathrm{M}$ $\mathrm{KOH}$ electrolyte. When deposited on $\mathrm{Ni}$ foam, the $a-\mathrm{CoVO}_{x}$ reached reached $10 \mathrm{~mA} \mathrm{~cm}{ }^{-2}$ at a $254 \mathrm{mV}$ overpotential, making it among the most active electrodes in alkaline conditions. The activity of various $a-\mathrm{CoVO}_{x}$ samples with different $\mathrm{Co}: \mathrm{V}$ ratios correlates with the $\mathrm{M}-\mathrm{OH}$ bond strength in a volcano-type plot. This work demonstrates the utility of a simple descriptor ( $\mathrm{M}-\mathrm{OH}$ bond strength) for experimental developments of OER catalysts, and advocates the further exploration of vanadium-containing oxides in OER.

\section{EXPERIMENTAL SECTION}

All reagents were obtained from commercial sources and used without further purification. Millipore deionized water 18.2 $\mathrm{M} \Omega \cdot \mathrm{cm}$ was used to prepare all the solutions.

All the catalysts were prepared by hydrothermal synthesis in Teflon-lined stainless steel autoclaves. For $m-\mathrm{CoVO}_{x}$, an aqueous solution containing $30 \mathrm{mM}$ of cobalt(II) chloride ( $\mathrm{CoCl}_{2}$, anhydrous, > 98\%, Fluka), $10 \mathrm{mM}$ of vanadium(III) chloride $\left(\mathrm{VCl}_{3}\right.$, anhydrous, 97\%, Sigma), and $63 \mathrm{mM}$ urea (99\%, ACS reagent) was loaded into the autoclave and heated at $150{ }^{\circ} \mathrm{C}$ for $14 \mathrm{~h}$. The control samples $\left(\mathrm{CoO}_{x}\right.$ and $\left.\mathrm{VO}_{x}\right)$, based on only one of the two metals, were prepared by the same procedure except only the desired metal salt $\left(\mathrm{CoCl}_{2}\right.$ or $\mathrm{VCl}_{3}$ ) was used with a concentration of $40 \mathrm{mM}$ to keep the total amount of metal cations constant. After the hydrothermal step, the powders were separated by centrifugation at $6000 \mathrm{rpm}$ for $10 \mathrm{~min}$ and washed three times with a 50:50 mixture of $\mathrm{H}_{2} \mathrm{O}$ and ethanol, with centrifugation between each washing step. The powders were then collected and dried overnight under vacuum at room temperature.

The amorphous pure-phase catalysts $\left(a-\mathrm{CoVO}_{x}\right)$ were prepared following a procedure similar to the one described above. The only modifications were the addition of $80 \mathrm{mM}$ trisodium citrate (TSC, anhydrous, 98\%, Acros), and purging the solution with $\mathrm{N}_{2}$ a $a-\mathrm{CoVO}_{x}$ with different $\mathrm{Co}: \mathrm{V}$ atomic 
ratios $\left(a-\mathrm{Co}_{y} \mathrm{~V}_{1-y} \mathrm{O}_{x}\right)$ were synthesized by tuning the ratio of starting materials $\left(\mathrm{CoCl}_{2}\right.$ and $\left.\mathrm{VCl}_{3}\right)$ while keeping the total metal cation concentration at $40 \mathrm{mM}$.

The prepared catalyst powders $(5 \mathrm{mg})$ were each sonicated twice for $30 \mathrm{~min}$ in a mixture of $\mathrm{H}_{2} \mathrm{O}(1 \mathrm{~mL}),{ }^{\mathrm{i}} \mathrm{PrOH}(0.25$ $\mathrm{mL})$ and a Nafion solution ( $10 \mu \mathrm{L}, 5$ wt \% in EtOH, DuPont) in order to make an homogeneous suspension. Then, $2.5 \mu \mathrm{L}$ of this suspension was drop cast on a glassy carbon electrode $(\mathrm{CH}$ Instruments) with a diameter of $3 \mathrm{~mm}$ and previously polished (with $0.05 \mu \mathrm{m}$ gamma alumina powder on a microcloth polishing pad, $\mathrm{CH}$ Instruments). The drop was allowed to dry in ambient conditions for $30 \mathrm{~min}$. The catalyst loading was 140 $\mu \mathrm{g} \mathrm{cm}^{-2}$ in all cases.

The catalysts were also synthesized on nickel foam (thickness $1.6 \mathrm{~mm}$, porosity 95\%, Goodfellow Cambridge Limited) by putting the nickel foam substrate in the same solutions as for the hydrothermal synthesis and heating at $150{ }^{\circ} \mathrm{C}$ for $14 \mathrm{~h}$. The active area was delimited by applying epoxy glue (SPI Supplies) on the nickel foam and carefully pressing on it with a metal rod to make it fill all the pores in order to prevent electrolyte from reaching the potentiostat clamp by capillary action.

The OER activity and stability were measured by cyclic voltammetry and chronopotentiometry using a Metrohm Autolab potentiostat/galvanostat. The third CV was taken as representative measurement for all samples on glassy carbon and the tenth $\mathrm{CV}$ for the nickel foam substrates. A threeelectrode setup was used with either the glassy carbon electrode or nickel foam substrate as working electrode, a platinum wire as counter electrode, and $\mathrm{Ag} / \mathrm{AgCl}$ (sat. $\mathrm{KCl}$ ) as reference electrode. Stirring was performed only during the stability measurements. Standard $1 \mathrm{M} \mathrm{KOH}$ solution ( $\mathrm{pH}$ 13.6, Merk) and $\mathrm{NaOH}$ solution ( $\mathrm{pH}$ 13.6, Reactolab) were used as received and/or further purified to remove trace iron using a procedure reported by the Boettcher group. ${ }^{12}$

The uncompensated resistance for each sample was measured by electrochemical impedance spectroscopy (EIS) in order to correct for the $i R$ drop. The EIS data were collected at $1.20 \mathrm{~V}$ vs RHE and by applying 41 frequencies from $100 \mathrm{kHz}$ to $1 \mathrm{~Hz}(10 \mathrm{mV}$ amplitude). The resistance was determined to be $0.6-0.8 \Omega \mathrm{cm}^{2}$ for the samples on glassy carbon, and 1.0$1.4 \Omega \mathrm{cm}^{2}$ on nickel foam.

The faradaic efficiency was measured using an airtight glass $\mathrm{H}$-cell with an optical fluorescence sensor (Ocean Optics). Quantification was done for $a-\mathrm{Co}_{0.75} \mathrm{~V}_{0.25} \mathrm{O}_{x}$ deposited on nickel foam. The cell was purged with $\mathrm{N}_{2}$ to give an initial $\mathrm{O}_{2}$ content lower than $0.5 \%$. The measurement was done at $10 \mathrm{~mA} \mathrm{~cm}^{-2}$ in $1 \mathrm{M}$ Fe-free $\mathrm{KOH}$.

The X-ray powder diffraction (XRD) was recorded on a PANalytical Empyrean diffractometer with Bragg-Brentano geometry, equipped with a PIXcel-1D detector. For the measurement, powders were mixed with EtOH and dropdried on glass slides. Data were analyzed with PANanalytical X'Pert HighScore software. XPS analysis was carried out using a PHI VersaProbe II scanning XPS microprobe with monochromatic $\mathrm{Al} \mathrm{K} \alpha \mathrm{X}$-ray source of $24.8 \mathrm{~W}$ with a beam size of $100 \mu \mathrm{m}$. The adventitious carbon $1 \mathrm{~s}$ peak was calibrated at $284.8 \mathrm{eV}$ and used as an internal standard to compensate for charging effects. Data were fitted by using PHI MultiPak software. SEM images were taken using a Zeiss Merlin microscope operated at $2 \mathrm{kV}$ and equipped with an Inlens secondary electron detector. TEM images and STEM/EDX maps were recorded using a FEI Technai Osiris TEM/STEM operated at $200 \mathrm{kV}$ equipped with a high-brightness XFEG gun and with a FEI Talos operated at $200 \mathrm{kV}$. TEM samples were prepared by drop-drying either suspension of the powders in EtOH onto carbon coated copper grids or a suspension made by sonicating the nickel foam electrode for $30 \mathrm{~min}$ in EtOH to detached catalyst particles from the NF surface

\section{ASSOCIATED CONTENT}

\section{S Supporting Information}

The Supporting Information is available free of charge on the ACS Publications website at DOI: 10.1021/acscatal.7b03198.

Experimental and spectral data (PDF)

\section{AUTHOR INFORMATION}

\section{Corresponding Author}

*E-mail: xile.hu@epfl.ch.

\section{ORCID}

Xile Hu: 0000-0001-8335-1196

\section{Author Contributions}

The manuscript was written through contributions of all authors and they have given their approval to the final version of the manuscript.

Notes

The authors declare no competing financial interest.

\section{ACKNOWLEDGMENTS}

This project has received funding from the European Research Council (ERC) under the European Union's Horizon 2020 research and innovation programme (grant agreement no. 681292). The authors thank Dr. Fang Song (EPFL) for the TEM and STEM-EDX measurements, Dr. Jordan Katz (Denison University) for editing and proofreading of the manuscript, and Ms. Prune Hu (Suricate Design) for the Table of Content graphic.

\section{REFERENCES}

(1) Lewis, N. S.; Nocera, D. G. Proc. Natl. Acad. Sci. U. S. A. 2006, 103, 15729-15735.

(2) (a) Lee, Y.; Suntivich, J.; May, K. J.; Perry, E. E.; Shao-Horn, Y. J. Phys. Chem. Lett. 2012, 3, 399-404. (b) Cook, T. R.; Dogutan, D. K.; Reece, S. Y.; Surendranath, Y.; Teets, T. S.; Nocera, D. G. Chem. Rev. 2010, 110, 6474-6502.

(3) (a) Yeo, B. S.; Bell, A. T. J. Am. Chem. Soc. 2011, 133, 55875593. (b) Smith, R. D. L.; Prévot, M. S.; Fagan, R. D.; Zhang, Z.; Sedach, P. A.; Siu, M. K. J.; Trudel, S.; Berlinguette, C. P. Science 2013, 340, 60-63. (c) Trotochaud, L.; Ranney, J. K.; Williams, K. N.; Boettcher, S. W. J. Am. Chem. Soc. 2012, 134, 17253-17261.

(4) McCrory, C. C. L.; Jung, S.; Peters, J. C.; Jaramillo, T. F. J. Am. Chem. Soc. 2013, 135, 16977-16987.

(5) Louie, M. W.; Bell, A. T. J. Am. Chem. Soc. 2013, 135, 1232912337.

(6) Bockris, J. O. M.; Otagawa, T. J. Electrochem. Soc. 1984, 131, 290-302.

(7) Suntivich, J.; May, K. J.; Gasteiger, H. A.; Goodenough, J. B.; Shao-Horn, Y. Science 2011, 334, 1383-1385.

(8) Man, I. C.; Su, H. Y.; Calle-Vallejo, F.; Hansen, H. A.; Martínez, J. I.; Inoglu, N. G.; Kitchin, J.; Jaramillo, T. F.; Nørskov, J. K.; Rossmeisl, J. ChemCatChem 2011, 3, 1159-1165.

(9) Grimaud, A.; May, K. J.; Carlton, C. W.; Lee, Y. L.; Risch, M.; Hong, W. T.; Zhou, J.; Shao-Horn, Y. Nat. Commun. 2013, 4, 2439.

(10) Morales-Guio, C. G.; Liardet, L.; Hu, X. J. Am. Chem. Soc. 2016, 138, 8946-8957.

(11) (a) Friebel, D.; Louie, M. W.; Bajdich, M.; Sanwald, K. E.; Cai, Y.; Wise, A. M.; Cheng, M. J.; Sokaras, D.; Weng, T. C.; Alonso-Mori, R.; Davis, R. C.; Bargar, J. R.; Nørskov, J. K.; Nilsson, A.; Bell, A. T. J. 
Am. Chem. Soc. 2015, 137, 1305-1313. (b) Stevens, M. B.; Trang, C. D. M.; Enman, L. J.; Deng, J.; Boettcher, S. W. J. Am. Chem. Soc. 2017, 139, 11361-11364. (c) Burke, M. S.; Kast, M. G.; Trotochaud, L.; Smith, A. M.; Boettcher, S. W. J. Am. Chem. Soc. 2015, 137, 36383648.

(12) Trotochaud, L.; Young, S. L.; Ranney, J. K.; Boettcher, S. W. J. Am. Chem. Soc. 2014, 136, 6744-6753.

(13) Eftekhari, A. Mater. Today Energy 2017, 5, 37-57.

(14) Fan, K.; Chen, H.; Ji, Y.; Huang, H.; Claesson, P. M.; Daniel, Q.; Philippe, B.; Rensmo, H.; Li, F.; Luo, Y.; Sun, L. Nat. Commun. 2016, 7, 11981.

(15) Shi, H.; Liang, H.; Ming, F.; Wang, Z. Angew. Chem., Int. Ed. 2017, 56, 573-577.

(16) Corrigan, D. J. Electrochem. Soc. 1987, 134, 377-384.

(17) Borod'ko, Y. G.; Vetchinkin, S. I.; Zimont, S. L.; Ivleva, I. N.; Shul'ga, Y. M. Chem. Phys. Lett. 1976, 42, 264-267.

(18) (a) Biesinger, M. C.; Lau, L. W. M.; Gerson, A. R.; Smart, R. S. C. Appl. Surf. Sci. 2010, 257, 887-898. (b) Silversmit, G.; Depla, D.; Poelman, H.; Marin, G. B.; De Gryse, R. J. Electron Spectrosc. Relat. Phenom. 2004, 135, 167-175.

(19) Moulder, J. F.; Stickle, W. F.; Sobol, P. E.; Bomben, K. D. Handbook of X-ray Photoelectron Spectroscopy; Physical Electronics Inc: Eden Prairie, MN, 1995; pp 41, 45, 83.

(20) Peng, X.; Wang, L.; Hu, L.; Li, Y.; Gao, B.; Song, H.; Huang, C.; Zhang, X.; Fu, J.; Huo, K.; Chu, P. K. Nano Energy 2017, 34, 1-7.

(21) Xing, M.; Kong, L. B.; Liu, M. C.; Liu, L. Y.; Kang, L.; Luo, Y. C. J. Mater. Chem. A 2014, 2, 18435-18443.

(22) Zhang, J.; Yuan, B.; Cui, S.; Zhang, N.; Wei, J.; Wang, X.; Zhang, D.; Zhang, R.; Huo, Q. Dalton Trans. 2017, 46, 3295-3302.

(23) Chou, N. H.; Ross, P. N.; Bell, A. T.; Tilley, T. D. ChemSusChem 2011, 4, 1566-1569.

(24) Jiang, J.; Zhang, A.; Li, L.; Ai, L. J. Power Sources 2015, 278, $445-451$.

(25) Chen, S.; Duan, J.; Jaroniec, M.; Qiao, S. Z. Angew. Chem., Int. Ed. 2013, 52, 13567-13570.

(26) Zhu, Y. P.; Liu, Y. P.; Ren, T. Z.; Yuan, Z. Y. Adv. Funct. Mater. 2015, 25, 7337-7347.

(27) Fabbri, E.; Habereder, A.; Waltar, K.; Kotz, R.; Schmidt, T. J. Catal. Sci. Technol. 2014, 4, 3800-3821. 